\title{
Effect of soil organic matter content on plant uptake factor of ginseng for endosulfan
}

\author{
${\text { Kyeong-Yeol } \mathrm{Oh}^{1} \text { (D) } \cdot \text { Geun-Hyoung Choi }}^{2}$ (D) $\cdot$ Ji-Yeon Bae $^{1}$ (D) $\cdot$ Deuk-Yeong Lee $^{1}$ (D) $\cdot$ \\ Sung-Woo Lee $^{3} \cdot$ Jin-Hyo Kim ${ }^{1}$ if
}

\section{토양유기물 함량이 인삼근의 endosulfan 홉수이행에 미치는 영향}

\author{
오경열 ${ }^{1}$ · 최근형 ${ }^{2} \cdot$ 배지연 $^{1} \cdot$ 이득영 $^{1} \cdot$ 이성우 $^{3}$ - 김진효 ${ }^{1}$
}

Received: 8 October 2020 / Accepted: 5 November 2020 / Published Online: 31 December 2020

(C) The Korean Society for Applied Biological Chemistry 2020

\begin{abstract}
The plant uptake of endosulfan, a new persistent organic pollutants from soil environment was investigated on ginseng through the field survey in Korea. The endosulfan residues in soil for this survey were ranged on $0.013-0.136 \mathrm{mg} \mathrm{kg}^{-1}$. The plant uptake factor (PUF) for endosulfan in ginseng was 0.243-1.708 and the highest PUF was found on 3-year-old ginseng. The PUF for endosulfan decreased in the longer cultivation period and it might be caused by the dilution effect of ginseng growth. In addition, the soil organic matter (SOM) content affected on the PUF negatively and Pearson correlation coefficient (r) between SOM and PUF was $-0.7812(p<0.05)$. Thus, higher SOM would positively affect to reduce the endosulfan residue in ginseng root.
\end{abstract}

Keywords Endosulfan - Ginseng · Persistent organic pollutants - Plant uptake factor $\cdot$ Soil organic matter

Jin-Hyo Kim $(\bowtie)$

E-mail: jhkim75@gnu.ac.kr

${ }^{1}$ Department of Agricultural Chemistry, Institute of Agriculture and Life Science (IALS), Gyeongsang National University, Jinju 52828, Republic of Korea

${ }^{2}$ Chemical Safety Division, National Institute of Agriculture Science, RDA, Wanju 55365, Republic of Korea

${ }^{3}$ Department of Herbal Crop Research, National Institute of Horticultural and Herbal Science, RDA, Eumsung 27709, Republic of Korea

This is an Open Access article distributed under the terms of the Creative Commons Attribution Non-Commercial License (http://creativecommons. org/licenses/by-nc/3.0/) which permits unrestricted non-commercial use, distribution, and reproduction in any medium, provided the original work is properly cited.
서 론

Endosulfan은 흰가루이, 진딧물, 멸구, 감자잎벌레 등 다양한 해 충 방제에 사용된 유기염소계 농약이었으나, 최근 높은 환경 잔 류성과 난분해성, 장거리 이동성 및 잔류독성이 문제되어 국내 에서는 2012년 사용금지 되었고, Stockholm Convention에서 잔 류성유기오염물질(Persistent Organic Pollutants)로 지정되었다[15]. 하지만, endosulfan의 사용이 전면 금지되었음에도 불구하고, 이들의 높은 환경 잔류성으로 인해 최근까지 경작지 토양과 작 물에서의 잔류가 빈번히 확인되고 있다[6-9]. 특히, Park 등[9] 의 연구에서 국내 밭 토양의 endosulfan 검출율은 최대 $70 \%$ 에 이르는 것으로 보고된 바 있고, 국내 생산 주요작물에서의 잔 류도 꾸준히 확인되고 있다[10]. 따라서, 토양 잔류 endosulfan 의 작물 흡수이행성과 이로 인한 작물 잔류 위해성 문제의 해 결을 위하여 작물 가식부에 대한 흡수이행성 연구의 필요성이 높아지고 있다.

인삼은 다년생의 근채류로 분류된 작물로, 4-6년근을 수확하 여 식품 혹은 생약용으로 사용하고 있다. 특히, 인삼의 주요 약 리성분인 ginsenoside는 항암, 혈압조절, 간 기능개선 및 항염증 등의 효과가 밝혀지면서 다양한 건강기능성 식품의 원료로 사 용되고 있고, 우리나라 건강기능식품 원료 중 생산 비중이 가 장 높은 작물이다[11-15]. 하지만, 타 작물에 비해 긴 경작기간 과 이로 인한 병해충의 발생 위협으로 다양한 종류의 농약이 사용되고 있으며, 이들의 잔류 또한 엄격하게 관리되고 있다. 최근 $\operatorname{Lim}$ 등[16]의 보고에 따르면, 인삼 중 잔류농약 부적합율 은 $2.1 \%$ 수준으로 전체 농산물 부적합율과 유사한 수준으로 확 인된 바 있다. 하지만, 최근 조사에서도 사용금지 농약인 endosulfan이 지속적으로 검출됨에 따라, endosulfan에 대한 경 작지 잔류와 인삼근 잔류의 흡수이행에 관한 연구 및 이를 통 한 인삼 경작지 토양의 endosulfan 안전관리 지침 마련의 필요 
성이 증가하고 있다.

토양 잔류 endosulfan의 작물 흡수이행은 생물농축계수 (bioconcentration factor)나 식물흡수이행계수(plant uptake factor, PUF)를 산출하여 활용하고 있으며, 지금까지 시금치, 당근, 무, 감자 등 채소류와 쌀 등 곡류에서 endosulfan의 흡수이행에 관 한 연구 결과가 일부 보고된 바 있다[2,3,6,17,18]. 하지만, 조사 된 작물 대부분은 재배기간이 일년 미만으로 짧은 작물이었으 며, 인삼과 같은 다년생 재배작물에 대한 잔류흡수이행 연구는 부족한 상황이다. 최근 $\mathrm{Kim}$ 등[19]은 endosulfan 신규오염지를 조성하여 2년근 인삼을 대상으로 토양과 인삼근의 잔류를 조사 하였고, 이를 통해 PUF를 산출해보면 토양의 초기 잔류농도를 기준으로 할 경우 1.140-4.570이었고, 인삼 시료채취 시점의 토 양 잔류농도를 반영할 경우 2.465-7.469이었다. 하지만, endosulfan 등이 신규 오염된 토양에서는 숙성과정을 거치게 되면 오염물 질은 토양교질 및 토양 유기물(soil organic matter, SOM) 등과 함께 결합하거나 흡착 안정화되며, 이에 따라, 토양에서의 이동 성과 잔류성은 숙성과정을 통해 크게 달라진다[20-23]. 따라서, 2012년 이후 신규 사용이 금지된 endosulfan의 인삼근 흡수이 행에 관한 연구를 위해서는 충분히 숙성된 토양에서의 시험 평 가가 중요하다. 또한, 다양한 연구자들에 의해 보고된 바와 같 이 endosulfan의 PUF는 동일작물에서도 재배환경에 따라 큰 편 차를 가질 수 있다[2,3,6,17,18,22]. 이는 경작지 토양특성 및 재 배 기상환경, 작물 생육 등에 의한 복합적인 영향으로 평가되 고 있다. 이에 따라, 본 연구에서는 인삼근에서 endosulfan의 흡 수이행성을 평가하기 위해 토양 잔류조사를 실시한 후 토양 잔 류가 확인된 경작지에서 재배 중인 인삼근을 채취하여 PUF를 평가하였다. 또한, $\mathrm{SOM}$ 과 $\mathrm{PUF}$ 의 연관성을 평가하고자 다양한 지역에서 채취한 인삼 경작지 토양특성을 분석하고, PUF와 $\mathrm{SOM}$ 과의 상관성을 분석하였다.

\section{재료 및 방법}

\section{표준품 및 시약}

Endosulfan 분석용 표준품인 $\alpha$-endosulfan, $\beta$-endosulfan과 endosulfan sulfate는 Dr. Ehrenstorfer GmbH (Augsburg, Germany)에서 구입하여 사용하였고, 시험에 사용한 용매인 acetone, acetonitrile, EtOAc, $n$-hexane, dichloromethane은 Merck KGaA (Darmstadt, Germany)에서 구입하여 사용하였으며, $\mathrm{MgSO}_{4}$ anhydrous와 $\mathrm{NaCl}, \mathrm{NaOH}$, trisodium citrate anhydrous는 Daejung Chemicals \& Metals Co. Ltd. (Siheung, Korea)에서 구입하여 사용하였다. Acetic acid와 $\mathrm{NH}_{4} \mathrm{CH}_{3} \mathrm{CO}_{2}, \mathrm{NH}_{4} \mathrm{~F},\left(\mathrm{NH}_{4}\right)_{2} \mathrm{SO}_{4}$, lactic acid는 Sigma-Aldrich Inc. (Darmstadt, Germany)에서 구입하여 사용하 였고, syringe filter (PTFE, $0.2 \mu \mathrm{m}$ )는 BIOFACT Co., Ltd. (Daejeon, Korea)에서 구입하여 사용하였다. 추출에 사용한 $\mathrm{rOQ}^{\mathrm{TM}}$ QuEChERS kit $\left(4 \mathrm{~g} \mathrm{MgSO}_{4}, 1 \mathrm{~g} \mathrm{NaCl}, 1 \mathrm{~g}\right.$ trisodium citrate dihydrate, $0.5 \mathrm{~g}$ disodium citrate sesquihydrate)는 Phenomenex Inc. (Torrance, CA, USA)의 제품을 사용하였고, Solid phase extraction (SPE) 정제에 사용한 Florisil cartridge $(1.0 \mathrm{~g}, 6 \mathrm{cc})$ 는 Applied Separations, Inc. (Allentown, PA, USA)의 제품을 사용하였고, dispersive-SPE (d-SPE) 정제에 사용한 BEKOlut ${ }^{\mathbb{R}}$
d-SPE kit (150 mg primary secondary amine, $150 \mathrm{mg} \mathrm{C18,}$ $900 \mathrm{mg} \mathrm{MgSO}_{4}$ )는 BEKOlut $\mathrm{GmbH} \&$ Co. KG (BruchmühlbachMiesau, Germany)의 제품을 사용하였다.

\section{Endosulfan 잔류 분석시료 채취}

Endosulfan 오염이 의심되는 인삼 시험포장에서 3년근 이상의 수삼 20-40근을 채취한 후 연구실까지 냉장보관하여 이동하였 다. 채취한 수삼은 흐르는 물로 세척하여 훍을 제거한 뒤 드라 이아이스를 사용하여 곱게 분쇄하고 $-20{ }^{\circ} \mathrm{C}$ 서 분석 전까지 보 관하였다. 잔류분석을 위한 토양 시료는 인삼을 채취한 위치에 서 표층부터 $0.3 \mathrm{~m}$ 깊이까지 토양채취기를 사용하여 $5 \mathrm{~kg}$ 이상 채취하였다. 수집한 토양은 실내 후드 내에서 4-5일간 음건하고, $2 \mathrm{~mm}$ 체를 사용하여 거른 후 $2 \mathrm{~mm}$ 이하의 토양만 분석용 시 료로 준비하였고, 시료분석 전까지 $-20^{\circ} \mathrm{C}$ 서 보관하였다.

\section{인삼경작지 토양의 이화학성 분석}

토양 이화학성 분석은 농촌진흥청 토양 및 식물체 분석법에 준 하여 Yoon 등[24]의 방법에 따라 수행되었다. 이를 요약하면 토 양 $\mathrm{pH}$ 는 토양과 증류수를 $1: 10$ 비율로 추출하여 $\mathrm{pH}$ meter (Jenway 3540, Cole-Parmer Ltd., Stone, UK)로 분석하였으며, 유효인산은 Lancaster법 $(0.33 \mathrm{M}$ acetic acid, $0.15 \mathrm{M}$ lactic acid, $0.03 \mathrm{M}$ ammonium fluoride, $0.05 \mathrm{M}$ ammonium sulfate, $0.2 \mathrm{M}$ sodium hydroxide)으로 추출한 후 UV-Spectrophotometer (Cary 50, Varian, Inc., Palo Alto, CA, USA)를 이용하여 720 $\mathrm{nm}$ 에서 흡광분석으로 측정하였다. 치환성 양이온은 $1.0 \mathrm{M}$ ammonium acetate $(\mathrm{pH}$ 7.0)을 사용하여 추출한 후 ICP-OES (Optima 5300DV, PerkinElmer, Inc., Waltham, MA, USA)를 이용하여 분석하였고, 토양 유기물함량은 Tyurin법을 이용하여 적정을 통해 산출하였다.

\section{Endosulfan 잔류 분석시료 전처리}

토양: 건조 토양시료 $5 \mathrm{~g}$ 에 acetonitrile $15 \mathrm{~mL}$ 를 가하여 진탕 후 $2 \mathrm{~g} \mathrm{MgSO}_{4}$ anhydrous와 $0.5 \mathrm{~g} \mathrm{NaCl}, 0.5 \mathrm{~g}$ trisodium citrate anhydrous를 첨가하여 1시간 동안 진탕 추출하고, $4000 \mathrm{rpm}$ 에서 10 분간 원심 분리 후 상등액 $9 \mathrm{~mL}$ 을 취하여 질소 농축하였다. 농축된 잔류물은 acetone $/ n$-hexane $(1 / 9, v / v)$ 혼합액 $1 \mathrm{~mL}$ 로 재 용해하고, Florisil SPE는 $n$-hexane $5 \mathrm{~mL}$ 및 acetone $/ n$-hexane $(1 / 9, v / v)$ 혼합액 $5 \mathrm{~mL}$ 를 차례로 가하여 conditioning 후 시료 를 loading하였다. 시료 loading 후 acetone/ $n$-hexane $(1 / 9, v / v)$ 혼합액 $5 \mathrm{~mL}$ 를 사용하여 3회 elution하고, 정제된 용리액을 질 소 농축하였다. 농축된 잔류물을 acetone $1 \mathrm{~mL}$ 에 재용해한 후 syringe filter로 여과하여 기기분석용 vial에 담은 후 GC-mass spectrometer $(\mathrm{MS})$ 로 정량분석 하였다.

인삼: 인삼 $10 \mathrm{~g}$ 에 acetonitrile $10 \mathrm{~mL}$ 를 넣고, 초음파 추출 후 $\mathrm{rOQ}^{\mathrm{TM}} \mathrm{QuEChERS}$ kit와 함께 1시간 동안 진탕 추출하였다. 이 후 $4000 \mathrm{rpm}$ 에서 10 분간 원심 분리하고, 상등액 $6 \mathrm{~mL}$ 를 취한 후 $\mathrm{BEKOlut}^{\mathbb{R}} \mathrm{d}-\mathrm{SPE}$ kit와 함께 vortexing하고 $4000 \mathrm{rpm}$ 에서 원심분리 하였다. 상등액 $3 \mathrm{~mL}$ 를 취한 뒤 질소 농축하고, 농축 된 잔류물은 acetone $1 \mathrm{~mL}$ 에 재용해한 후 syringe filter로 여과 하여 기기분석에 사용하였다. 
Table 1 GC-MS instrumental condition for endosulfan analysis

\begin{tabular}{|c|c|c|}
\hline Instrument & GC-MS (QP2020, Shimadzu Corporation, Kyoto, Japan) & \\
\hline Injection & $2 \mu \mathrm{L}\left(270^{\circ} \mathrm{C}\right)$ & \\
\hline Matrix & Soil & Ginseng \\
\hline Column & Rtx-5MS $(0.25 \mathrm{~mm} \times 30 \mathrm{~m}, 0.25 \mu \mathrm{m})$ & DB-17MS $(0.25 \mathrm{~mm} \times 30 \mathrm{~m}, 0.25 \mu \mathrm{m})$ \\
\hline Oven condition & $\begin{array}{l}\left.100{ }^{\circ} \mathrm{C} \text { (holding } 1 \mathrm{~min} \text {, ramping } 10{ }^{\circ} \mathrm{C} / \mathrm{min}\right) \rightarrow 200{ }^{\circ} \mathrm{C} \\
\left(\text { ramping } 3{ }^{\circ} \mathrm{C} / \mathrm{min}\right) \rightarrow 250{ }^{\circ} \mathrm{C}\left(\text { ramping } 20{ }^{\circ} \mathrm{C} / \mathrm{min}\right) \rightarrow 300{ }^{\circ} \mathrm{C} \\
\text { (holding } 5 \mathrm{~min} \text { ) }\end{array}$ & $\begin{array}{l}\left.100{ }^{\circ} \mathrm{C} \text { (holding } 1 \mathrm{~min} \text {, ramping } 20^{\circ} \mathrm{C} / \mathrm{min}\right) \rightarrow 180{ }^{\circ} \mathrm{C} \\
\left(\text { ramping } 8{ }^{\circ} \mathrm{C} / \mathrm{min}\right) \rightarrow 220^{\circ} \mathrm{C}\left(\text { ramping } 15^{\circ} \mathrm{C} / \mathrm{min}\right) \rightarrow 300{ }^{\circ} \mathrm{C} \\
\text { (holding } 5 \mathrm{~min} \text { ) }\end{array}$ \\
\hline $\begin{array}{r}\text { Detection (SIM) } \\
\alpha \text {-Endosulfan }\end{array}$ & $\begin{array}{l}195 \mathrm{~m} / z \text { (Quantitative ion) } \\
207,241 \mathrm{~m} / \mathrm{z} \text { (Qualitative ions) }\end{array}$ & $\begin{array}{l}207 \mathrm{~m} / z \text { (Quantitative ion) } \\
195,241 \mathrm{~m} / \mathrm{z} \text { (Qualitative ions) }\end{array}$ \\
\hline$\beta$-Endosulfan & $\begin{array}{l}195 \mathrm{~m} / z \text { (Quantitative ion) } \\
207,241 \mathrm{~m} / z \text { (Qualitative ions) }\end{array}$ & $\begin{array}{l}207 m / z \text { (Quantitative ion) } \\
195,241 \mathrm{~m} / z \text { (Qualitative ions) }\end{array}$ \\
\hline Endosulfan sulfate & $\begin{array}{l}272 \mathrm{~m} / z \text { (Quantitative ion) } \\
229,241 \mathrm{~m} / \mathrm{z} \text { (Qualitative ions) }\end{array}$ & $\begin{array}{l}272 \mathrm{~m} / z \text { (Quantitative ion) } \\
229,387 \mathrm{~m} / \mathrm{z} \text { (Qualitative ions) }\end{array}$ \\
\hline
\end{tabular}

Table 2 Quantitative analysis method validation for endosulfan in soil and ginseng

\begin{tabular}{|c|c|c|c|c|c|c|}
\hline \multirow{2}{*}{$\begin{array}{c}\text { Matrix } \\
\text { Endosulfan congener }\end{array}$} & \multicolumn{3}{|c|}{ Soil } & \multicolumn{3}{|c|}{ Ginseng } \\
\hline & $\alpha-$ & $\beta-$ & -sulfate & $\alpha-$ & $\beta-$ & -sulfate \\
\hline Linearity $\left(\mathrm{R}^{2}\right)$ & 0.9997 & 0.9992 & 0.9994 & 1.0000 & 0.9998 & 0.9992 \\
\hline MLOQ $\left(\mathrm{mg} \mathrm{kg}^{-1}\right)$ & 0.002 & 0.002 & 0.002 & 0.002 & 0.002 & 0.002 \\
\hline Recovery (\%) & 74.5 & 86.3 & 84.7 & 85.2 & 78.6 & 107.5 \\
\hline CV (\%) & 7.2 & 9.5 & 8.4 & 8.8 & 4.9 & 5.9 \\
\hline
\end{tabular}

\section{GC-MS 기기분석 조건}

토양잔류 endosulfan의 분석에는 아래의 Table 1과 같은 조건에 서 Rtx-5MS 칼럼 $(0.25 \mathrm{~mm} \times 30 \mathrm{~m}, 0.25 \mu \mathrm{m}$, Restek Co., Bellefonte, $\mathrm{PA}, \mathrm{USA})$ 을 사용하여 분리하였으며, selectied ion mornitorin (SIM) 방법으로 검출하였다. 정량이온으로 $\alpha$-와 $\beta$-endosulfan은 $195 \mathrm{~m} / \mathrm{z}$ 를 각각 사용하였고, endosulfan sulfate는 $272 \mathrm{~m} / \mathrm{z}$ 를 사용하였다. 인삼 잔류 endosulfan은 DB-17MS 칼럼 $(0.25 \mathrm{~mm}$ $\times 30 \mathrm{~m}, 0.25 \mu \mathrm{m}$, Agilent Technology Inc., Santa Clara, CA, USA)을 사용하여 분리하였고, 정량이온으로 $\alpha$-와 $\beta$-endosulfan 은 $207 \mathrm{~m} / \mathrm{z}$ 를 각각 사용하였고, endosulfan sulfate는 $272 \mathrm{~m} / \mathrm{z}$ 를 사용하였다(Table 1).

\section{흡수이행계수 및 통계처리}

PUF는 Choi 등[25]과 Liu 등[26,27]의 방법과 같이 인삼 중 잔 류농도와 시료 채취시점의 토양 중 잔류농도를 사용하여 아래 의 Eq. (1)로 산출하였다.

$$
\text { PUF }=\frac{\text { Concentration in crop }\left(\mathrm{mg} \mathrm{kg}_{\text {f.w. }}^{-1}\right)}{\text { Concentration in soil }\left(\mathrm{mg} \mathrm{kg}_{\text {d.w. }}^{-1}\right)}
$$

통계처리를 위한 분석은 통계프로그램인 $\mathrm{SigmaPlot}^{\circledR}$ (ver. 12.0, Systat Software, Inc., San Jose, CA, USA)을 사용하였다.

\section{Endosulfan 분석법 검중}

$\alpha$-Endosulfan과 $\beta$-endosulfan, endosulfan sulfate는 0.005-1.000 $\mathrm{mg} \mathrm{L}^{-1}$ 의 농도구간에서 검량선을 작성하였고, linearity $\left(\mathrm{R}^{2}\right)$ 은 endosulfan conger 모두 0.999 이상이었다. 정량한계(Limit of quantification, LOQ)는 $10 \mathrm{signal} / \mathrm{noise}$ 를 기준으로 설정하였고, 본 시험법의 분석정량한계 (Method limit of quantification,
MLOQ)는 endosulfan conger 모두 $0.002 \mathrm{mg} \mathrm{kg}^{-1}$ 이었다. 토양과 인삼에서의 endosulfan conger별 회수율은 74.5-107.5\%이었고, 분석 변이계수(Coefficient of variation, $\mathrm{CV}$ )는 4.9-9.5\%이었다 (Table 2).

\section{결과 및 고찰}

\section{인삼경작지 토양의 이화학적 특성}

경작지 토양의 이화학성은 endosulfan의 흡탈착에 중요한 영향 을 미칠 수 있으며, 토양과의 강한 흡착은 총 endosulfan 대비 용탈성 endosulfan을 줄임으로서 작물로의 흡수이행이 가능한 endosulfan의 양을 감소시킬 수 있다. Endosulfan에 대한 토양 교 질의 흡착속도는 $\alpha$-와 $\beta$-endosulfan을 대상으로 수행된 연구에서 $0.4-2.3 \mathrm{mg} \mathrm{g}^{-1} \mathrm{~h}^{-1 / 2}$ 이었고, 흡착용량은 clay에서 $0.448 \mathrm{mg} \mathrm{g}^{-1}$ 로 가 장 높았으며, sandy soil에서 가장 낮은 $0.094 \mathrm{mg} \mathrm{g}^{-1}$ 이 보고되 었다. 또한, 높은 $\mathrm{pH}$ 에서 흡착량이 증가하는 것으로 보고된 바 있다[28,29]. 본 연구에서 조사된 인삼 경작지 토양의 토성은 loam이 가장 많았으며, sandy loam 및 silty loam 등도 확인되 었다. 이에 따라 토양 교질에 의한 흡착량은 앞서 보고된 문헌 을 참고하면 $0.5 \mathrm{mg} \mathrm{g}^{-1}$ 을 넘지 않을 것으로 추정되었다. 또한, endosulfan은 $\mathrm{pH} 7$ 이상에서 화학적 가수분해가 원활히 진행되 어 endosulfan diol 등으로 분해되는 것이 보고된 바 있으나, 본 연구에서 조사된 토양의 $\mathrm{pH}$ 는 4.6-6.1의 산성토로 확인되어, endosulfan의 화학적 가수분해가 활발히 진행될 수 있는 $\mathrm{pH}$ 영 역은 아닌 것으로 확인되었다[30,31]. 토양 중 주요 양이온인 $\mathrm{K}^{+}, \mathrm{Ca}^{2+}, \mathrm{Mg}^{2+}$ 의 함량은 각각 $0.7-1.9,3.8-9.1,0.4-2.4 \mathrm{cmol}_{\mathrm{c}}$ $\mathrm{kg}^{-1}$ 를 나타냈으며, 유효인산 함량은 $510-1754 \mathrm{mg} \mathrm{kg}^{-1}$ 으로 경작 
Table 3 The properties of the soil for ginseng cultivated farm

\begin{tabular}{|c|c|c|c|c|c|c|c|}
\hline \multirow{2}{*}{ Site } & \multirow{2}{*}{ Texture } & \multirow{2}{*}{$\begin{array}{c}\mathrm{pH} \\
(1: 10)\end{array}$} & \multirow{2}{*}{$\begin{array}{c}\text { SOM } \\
\left(\mathrm{g} \mathrm{kg}^{-1}\right)\end{array}$} & \multicolumn{3}{|c|}{ Exchangeable cation $\left(\mathrm{cmol}_{\mathrm{c}} \mathrm{kg}^{-1}\right)$} & \multirow{2}{*}{$\begin{array}{l}\text { Available } \mathrm{P}_{2} \mathrm{O}_{5} \\
\quad\left(\mathrm{mg} \mathrm{kg}^{-1}\right)\end{array}$} \\
\hline & & & & $\mathrm{K}$ & $\mathrm{Ca}$ & $\mathrm{Mg}$ & \\
\hline A1 & Loam & 6.1 & 17.2 & 1.2 & 9.1 & 2.4 & 872 \\
\hline $\mathrm{A} 2$ & Loam & 6.0 & 19.8 & 1.6 & 8.6 & 2.2 & 687 \\
\hline $\mathrm{B} 1$ & Silty loam & 5.4 & 10.1 & 1.0 & 6.5 & 1.4 & 595 \\
\hline $\mathrm{B} 2$ & Silty loam & 5.2 & 14.9 & 1.1 & 6.8 & 1.2 & 872 \\
\hline $\mathrm{C} 1$ & Loam & 4.7 & 38.8 & 1.0 & 3.8 & 0.8 & 589 \\
\hline $\mathrm{C} 2$ & Loam & 4.8 & 34.6 & 0.8 & 7.2 & 0.6 & 1025 \\
\hline $\mathrm{D}$ & Sandy loam & 5.9 & 17.5 & 0.7 & 7.4 & 1.0 & 1326 \\
\hline $\mathrm{E}$ & Loam & 5.0 & 12.7 & 1.9 & 6.3 & 1.7 & 1754 \\
\hline $\mathrm{F}$ & Loam & 4.6 & 28.6 & 1.0 & 5.4 & 0.4 & 1137 \\
\hline G & Loam & 4.7 & 30.0 & 1.2 & 6.4 & 0.8 & 997 \\
\hline $\mathrm{H}$ & Loam & 5.7 & 19.0 & 0.9 & 5.3 & 1.4 & 510 \\
\hline
\end{tabular}

지의 비료 양분 관리에 따라 넓은 분포를 나타내는 것을 확인 할 수 있었다(Table 3).

Endosulfan과 같이 전하를 갖지 않는 비극성 잔류 물질은 $\mathrm{SOM}$ 과 강하게 결합하는 특성을 갖고 있다. 이러한 $\mathrm{SOM}$ 과의 흡착특성은 $K_{\mathrm{oc}}$ 값으로 표현할 수 있으며, 그 값이 높을수록 토 양에서의 이동성은 낮아진다. Wadaskar 등[32]의 보고에 따르면, endosulfan의 $K_{\mathrm{oc}}$ 는 289620 이상으로 토양 중 유기물과의 결합 이 높고, 이로 인한 이동성이 현저히 낮은 것으로 보고된 바 있 다. 특히, 본 시험에서 수집된 인삼 경작지의 $\mathrm{SOM}$ 함량은 $10.1-38.8 \mathrm{~g} \mathrm{~kg}^{-1}$ 으로 넓은 범위의 토양 유기물 함량을 갖는 것 이 확인되었고, 이는 토양 중 endosulfan의 부동화 및 작물 흡 수이행성에 큰 영향을 미칠 것으로 예상되었다.

\section{인삼 경작지 토양의 endosulfan 잔류}

경작지 endosulfan 잔류모니터링에서 잔류가 확인된 인삼 경작 지 11지점에서 채취한 토양의 endosulfan 잔류량을 평가한 결 과, 총 endosulfan 잔류량은 $0.013-0.136 \mathrm{mg} \mathrm{kg}^{-1}$ 이었으며, 평균 잔류량은 $0.057 \mathrm{mg} \mathrm{kg}^{-1}$ 이었다. 총 endosulfan에 대한 endosulfan sulfate의 기여율이 $88.9 \%$ 로 가장 높았으며, $\beta$-endosulfan $(10.3 \%)$, $\alpha$-endosulfan $(0.8 \%)$ 순의 기여도를 나타내었다. 과거 경작지에 사용된 endosulfan은 $\alpha$-와 $\beta$-endosulfan의 비가 2:1-7:3이었으 며, endosulfan sulfate는 이들의 산화과정을 통해 생성된 대사 물질로 알려져 있다[33]. 따라서, 본 조사 결과와 같이 인삼 경 작지 토양 중 $\alpha$-와 $\beta$-endosulfan의 잔류비가 낮고 endosulfan sulfate의 비가 높은 것은 endosulfan의 신규 오염이 아닌 과거 사용된 농약의 토양 잔류로 보는 것이 타당할 것이다(Table 4).

\section{인삼근의 endosulfan 잔류와 흡수이행성}

인삼근에 잔류하는 endosulfan은 근표면에 물리적으로 흡착되거 나 흡수이행과정을 통하여 인삼근 내에 잔류할 수 있고, 또한, 잔류농도는 인삼근의 수분함량 및 비대생장에 따라 달라질 수 있다. 본 시험에서 채취한 인삼근에 대한 잔류분석 결과 endosulfan에 대한 PUF값은 0.243-1.708로 넓은 범위에서 확인 되었다. 인삼의 생육 연수에 따른 PUF의 평균값은 3 년근 1.708 , 4년근 $0.928,5$ 년근 $0.643,6$ 년근 0.717 이었다. 또한, 동일 포장
Table 4 Endosulfan residue in the ginseng cultivated soil

\begin{tabular}{ccccc}
\hline \hline \multirow{2}{*}{ Site } & \multicolumn{4}{c}{ Soil residue $\left(\mathrm{mg} \mathrm{kg}^{-1}\right)$} \\
\cline { 2 - 4 } A1 & $\alpha$-Endosulfan $\beta$-Endosulfan Endosulfan sulfate & Total \\
\hline A2 & $<0.002$ & 0.011 & 0.013 & 0.024 \\
B1 & $<0.002$ & 0.010 & 0.018 & 0.028 \\
B2 & $<0.002$ & 0.006 & 0.077 & 0.083 \\
C1 & $<0.002$ & 0.004 & 0.044 & 0.046 \\
C2 & 0.003 & 0.011 & 0.085 & 0.089 \\
D & $<0.002$ & $<0.002$ & 0.122 & 0.136 \\
E & $<0.002$ & 0.004 & 0.013 & 0.023 \\
F & $<0.002$ & 0.004 & 0.062 & 0.017 \\
G & 0.002 & 0.012 & 0.083 & 0.096 \\
H & $<0.002$ & $<0.002$ & 0.013 & 0.013 \\
\hline
\end{tabular}

에서 인삼 생육연수를 달리하여 채취한 시료인 $\mathrm{A} 1$ 와 $\mathrm{A} 2$, 그리 고 $\mathrm{B} 1$ 와 $\mathrm{B} 2$ 및 $\mathrm{C} 1$ 와 $\mathrm{C} 2$ 의 비교를 통해서 생육연수 증가에 따 른 $\mathrm{PUF}$ 의 감소가 확인되었다. 인삼의 생육은 3 년근까지 전체 생장량의 $20 \%$ 미만으로 매우 느린 생장속도를 나타내지만, 4 년근(전체 생장량의 $43 \%$ )과 5 년근(전체 생장량의 $80 \%$ )에서 급 격한 비대생장을 나타내며 6년근까지 꾸준히 생장하는 것이 알 려져 있다[34,35]. 따라서, 인삼 생육연수 경과에 따른 endosulfan 의 PUF 감소는 인삼의 비대생장에 의한 희석효과가 주요 원인 일 것으로 판단되었다(Table 5).

\section{토양유기물과 인삼근의 endosulfan 홉수이행성}

Endosulfan의 높은 $K_{\mathrm{oc}}$ 를 고려하면, $\mathrm{SOM}$ 은 토양 중 endosulfan 과의 강한 흡착을 유도하여 인삼근의 endosulfan 흡수이행을 억 제하는데 기여할 것으로 추정되어, $\mathrm{SOM}$ 함량과 endosulfan에 대한 인삼근의 PUF 사이의 상관분석을 실시하였다. 그 결과 $5 \%$ 유의수준에서 SOM 함량이 증가할수록 endosulfan에 대한 인삼근의 PUF는 Fig. 1과 같이 감소하는 것이 확인되었고 $\left(\mathrm{R}^{2}=\right.$ $0.6102)$, Pearson의 상관계수 (r)는 -0.7812 로 PUF와 SOM 사 
Table 5 The residue in the cultivated ginseng and their PUF for total endosulfan

\begin{tabular}{cccc}
\hline \hline Site & $\begin{array}{c}\text { Total endosulfan } \\
\left(\mathrm{mg} \mathrm{kg}^{-1}\right)\end{array}$ & PUF & $\begin{array}{c}\text { Age of ginseng } \\
\text { (year) }\end{array}$ \\
\hline A1 & 0.041 & 1.708 & 3 \\
A2 & 0.021 & 0.750 & 4 \\
B1 & 0.097 & 1.169 & 4 \\
B2 & 0.033 & 0.717 & 6 \\
C1 & 0.055 & 0.618 & 4 \\
C2 & 0.033 & 0.243 & 5 \\
D & 0.021 & 0.913 & 5 \\
E & 0.020 & 1.176 & 4 \\
F & 0.027 & 0.409 & 5 \\
G & 0.033 & 0.340 & 5 \\
H & 0.017 & 1.308 & 5 \\
\hline
\end{tabular}

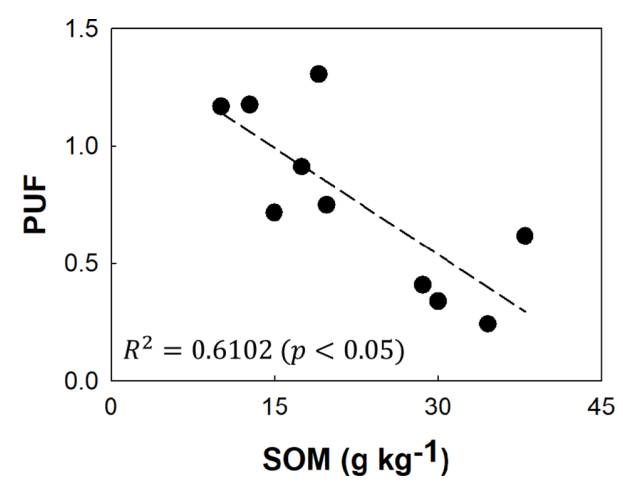

Fig. 1 The correlation with the SOM content of soil and the PUF of ginseng

이에는 강한 음의 상관관계가 있음을 확인하였다. 하지만, endosulfan에 대한 인삼근의 흡수이행 모델개발을 위해서는 생 육연수별 $\mathrm{PUF}$ 와 SOM 함량에 대한 추가조사 연구가 필요하 며, 이를 통해 endosulfan에 대한 인삼 경작지 토양안전관리 규 정을 마련할 수 있을 것이다.

현재 수삼에 대한 endosulfan의 최대잔류허용기준(Maximum residue limit, MRL)은 별도로 설정되어 있지 않으며, 근채류에 설정되어 있는 잠정 $\mathrm{MRL}$ 인 $0.1^{\mathrm{T}} \mathrm{mg} \mathrm{kg}$ 을 적용 받고 있다. 본 시험에서 수확된 수삼의 총 endosulfan 잔류는 현재의 안전관리 기준을 초과하지는 않았다.

\section{초 록}

본 연구에서는 경작지 포장 조사를 통한 인삼근의 endosulfan 흡수이행성(PUF)을 산출하고, 토양 유기물 함량과 endosulfan에 대한 인삼근의 PUF에 관한 상관성을 분석하였다. Endosulfan 흡수이행 시험포장의 총 endosulfan 잔류량은 $0.013-0.136 \mathrm{mg}$ $\mathrm{kg}^{-1}$ 이었다. Endosulfan에 대한 인삼근의 PUF는 0.243-1.708로 인삼근의 연령이 증가할수록 비대생장에 의한 PUF값 감소가 확 인되었다. 또한, 토양 유기물 함량과 endosulfan에 대한 인삼근
의 PUF값은 $5 \%$ 유의수준에서 음의 상관관계가 있음을 확인하 였다 $\left(\mathrm{R}^{2}=0.6102\right)$. 따라서, endosulfan 오염 우려지역에서의 인삼 경작을 위해서는 가급적 높은 토양유기물 함량을 유지하는 것 이 endosulfan의 흡수이행을 억제하는데 도움을 줄 수 있을 것 이다.

Keywords 엔도설판 · 인삼 · 잔류성유기오염물질 · 토양유기 물 · 흡수이행계수

Acknowledgment This study was supported by the "Research Program for Agricultural Science \& Technology Development (Project No. PJ01381603)", National Institute of Horticultural and Herbal Science, Rural Development Administration, Republic of Korea.

\section{References}

1. Bae JY, Lee DY, Choi IW, Lee JH, Kim JH (2019) Examination of commercial biochars to compare their endosulfan adsorption properties. Korean J Pestic Sci 23(3): 172-176

2. Choi GH, Lee DY, Seo DC, Kim LS, Lim SJ, Ryu SH, Park BJ, Kim JH, Kim JH (2018) Endosulfan plant uptake suppression effect on char amendment in oriental radish. Water Air Soil Pollut 229: 24

3. Hwang J, Zimmerman AR, Kim JE (2018) Bioconcentration factorbased management of soil pesticide residues:en do sulfan uptake by carrot and potato plants. Sci Total Environ 627: 514-522

4. Kim LS, Jeon JW, Son JY, Kim CS, Ye J, Kim HJ, Lee CH, Hwang SM, Choi SD (2020) Nationwide levels and distribution of endosulfan in air, soil, water, and sediment in South Korea. Environ Pollut 265: 1115035

5. Lee DY, Choi GH, Rho JH, Lee HS, Park SW, Oh KY, Kim JH (2020) Comparison of the plant uptake factor of perfluorooctanoic acid (PFOA) and perfluorooctane sulfonic acid (PFOS) from the three different concentrations of PFOA and PFOS in soil to spinach and Welsh onion. J Appl Biol Chem 63(3): 243-248

6. Choi GH, Lee DY, Ryu SH, Rho JH, Park BJ, Moon BC, Kim JH (2018) Investigation of the bioconcentration factor of endosulfan for rice from soil. Korean J Pestic Sci 22: 25-28

7. Hwang JI, Lee SE, Kim JE (2015) Plant uptake and distribution of endosulfan and its sulfate metabolite persisted in soil. PLoS One 10(11): e0141728

8. Lim SJ, Park JH, Rho JH, Oh YT, Joo HG, Lee MH, Yoon HI, Choi GH, Ryu SH, Park BJ (2018) Investigation of residueal organochlorine pesticides in grape and peach orchard soils and fruits. Korean J Pestic Sci 22: 292-299

9. Park BJ, Lee BM, Kim CS, Park KH, Park SW, Kwon HY, Kim JH, Choi GH, Lim SJ (2013) Long-term monitoring of pesticide residues in arable soils in Korea. Korean J Pestic Sci 17(4): 283-292

10. NAQS (2017) 2016 Annual report for quality management of agricultural products. National Agricultrual Products Quality Management Service, Gimcheon, Republic of Korea

11. Ahuja A, Kim JH, Kim JH, Yi YS, Cho JY (2018) Functional role of ginseng-derived compounds in cancer. J Ginseng Res 42: 248-254

12. Baeg IH, So SH (2013) The world ginseng market and the ginseng (Korea). J Ginseng Res 37(1): 1-7

13. Kim DM, Han JH (2019) Study on biosynthesis of ginsenosides in the leaf of Panax ginseng by seasonal flux analysis. J Appl Biol Chem 62: 315-322

14. Park JD (1996) Recent studies on the chemical constituents of Korean ginseng (Panax ginseng C.A. Meyer). J Ginseng Res 20(4): 389-415

15. Ru W, Wang D, Xu Y, He X, Sun YE, Qian L, Zhou X, Qin Y (2015) Chemical constituents and bioactivities of Panax ginseng (C. A. Mey.). Drug Discov Ther 9: 23-32 
16. Lim JH, Kim GL, Lim HJ, Hwang KG, Kim DH (2018) Monitoring and risk assessment of pesticides residues in preharvest ginseng (Panax ginseng C.A. Meyer) in Jeollabuk-do. Korean J Pestic Sci 22: 54-61

17. Choi GH, Jeong DK, Lim SJ, Rho JH, Ryu SH, Park BJ, Kim JH (2017) Plant uptake potential of endosulfan from soil by carrot and spinach. $\mathrm{J}$ Appl Biol Chem 60: 339-342

18. Hwang JI, Kwak SE, Lee SH, Kang MS, Ruy JS, Kang JG, Jung HH, Hong SH, Kim JE (2016) Establishment of safe management guideline based on uptake pattern of pesticide residue from soil by radish. Korean J Pestic Sci 35(4): 278-285

19. Kim JY, Saravanan M, Palansooriya KN, Hur JH (2018) Translocation of endosulfan from soil to ginseng (Panax ginseng C. A. Meyer). Agriculture 8: 52

20. Gautam SK, Suresh S (2006) Dechlorination of DDT, DDD and DDE in soil (slurry) phase using magnesium/palladium system. J Colloid Interface Sci 304: 144-151

21. Hussen A, Megerasa N, Jönsson Åke J (2017) Effect of aging organochlorine pesticides in various soil types on their extractability using selective pressurized liquid extraction. J Environ Prot 8: 867-883

22. Park SW, Yoo JH, Oh KS, Park BJ, Kim SS, Chon KM, Kwon HY, Hong SM, Moon BC, Choi H (2017) Uptake and translocation of the soil resi dual pesticides into the vegetable crop. Korean J Pestic Sci 23(3): 298-309

23. Tiwari MK, Guha S (2012) Role of soil organic matter on the sorption and cosorption of endosulfan and chlorpuyrifos on agricultural soil. J Envrion Eng 138: 426-435

24. Yoon YE, Im JU, Kim JH, Jeon SH, Jeong MS, Lee YB (2019) Effect of oil-cake and amino acid fertilizer on soil bio-chemical properties and pepper yield. Korean J Soil Sci Fert 52(3): 196-205

25. Choi GH, Lee DY, Bruce-Vanderpuije P, Song AR, Lee HS, Park SW, Lee JH, Megson D, Kim JH (2020) Environmental and dietary exposure of perfluorooctanoic acid and perfluorooctanesulfonic acid in the Nakdong River. Environ Geochem Health doi: 10.1007/s10653-020 00721-0
26. Liu Z, Lu Y, Shi Y, Wang P, Jones K, Sweetman AJ, Johnson AC, Zhang M, Zhou Y, Lu X, Su C, Sarvajayakesavaluc S, Khan K (2017) Crop bioaccumulation and human exposure of perfluoroalkyl acids through multi-media transport from a mega fluorochemical industrial park, China. Environ. Int 106: 37-47

27. Liu Z, Lu Y, Song X, Jones K, Sweetman AJ, Johnson AC, Zhang M, Lu $\mathrm{X}$, Su C (2019) Multiple crop bioaccumulation and human exposure of perfluoroalkyl substances around a mega fluorochemical industrial park, China: Implication for planting optimization and food safety. Environ Int 127: $671-684$

28. Kumar M, Philip L (2006) Adsorption and desorption characteristics of hydrophobic pesticide endosulfan in four Indian soils. Chemosphere 62: 1064-1077

29. Parkpian P, Anurakpongsatorn P, Pakkong P, Patrick Jr WH (1998) Adsorption, desorption and degradation of $\alpha$-endosulfan in tropical soils of Thailand. J Environ Sci Health B 33: 211-233

30. Ryoo KS, Kim MH, Lee HS, Hwang HG (2006) Photodegradation of endosulfan alpha, beta, and sulfate in aqueous solution by UV irradiation only. J Environ Sci Int 15: 1061-1067

31. Shivaramaiah HM, Sanchez-Bayo F, Al-Rifai J, Kennedy IR (2005) The fate of endosulfan in water. J Environ Sci Health B 40: 711-720

32. Wadaskar JV, Ekhe JD, Kale SP (2006) Adsorption-desorption of $\mathrm{HCH}$ and endosulfan on a soil. Environ Technol 27: 1011-1017

33. Weber J, Halsall CJ, Muir D, Teixeira C, Small J, Solomon K, Hermanson M, Hung H, Bidleman T (2010) Endosulfan, a global pesticide: A review of its fate in the environment and occurrence in the Arctic. Sci Total Environ 408: 2966-2984

34. Ah YN, Lee SY, Choung MG, Kang KH (2002) Optimum harvesting time based on grwoth characteristics of four-year ginseng. Korean J Crop Sci 47: 211-215

35. Kim MW, Ko SR, Choi KJ, Kim SC (1987) Distribution of saponin in various sections of Panax ginseng root and changes of its contents according to root age. J Ginseng Res 11: 10-16 